\title{
TRANSNASAL ENDOSCOPIC TREATMENT OF CHOANAL ATRESIA
}

\author{
*Mohamed Elsayed M.D.
}

Abstract: To evaluate the outcome of the repair of congenital choanal atresia (CCA) using the transnasal endoscopic approach with and without power instruments.This study was done on Eight patients with either unilateral or bilateral congenital choanal atresia were treated using the transnasal endoscopic approach. We describe our experience and follow-up of 8 patients (6 with unilateral atresia and 2 with bilateral atresia 1) that were treated with the use of the transnasal endoscopic technique during a 5-year period. In 5 patients, the transnasal endoscopic technique was performed using conventional biting instruments, and in 3 patients, the transnasal endoscopic technique with power instruments was used. No stent were used. Results: Of 8 patient procedures, 6 remained patent. One patient required minor debridement of granulation tissue 1 week and 1 patient had restenosis and revision done in 1 month.

\section{Introduction:}

The transnasal endoscopic route offers Excellent visualization of the posterior choanal and, hence, the ability to open the defect widely with a high surgical success rate. Newer powered instrumentation further enhances the ability to perform this technique. Congenital choanal atresia is a relatively rare malformation. The incidence is approximately 1 in 7000 to 8000 births. It occurs more frequently in females than males. Unilateral is more common than bilateral, and of those, the right side is more frequently affected. The purported mechanism is either a failure of buccopharyngeal membrane breakdown or persistence and misdirection of mesoderm in the nasal cavities during embryogenesis. The old classification scheme originally developed by Fraser in 1910, and perpetuate in the literature for decades, stated that the obstruction was $90 \%$ bony and $10 \%$ membranous.(1) A more modern analysis using computed tomography (CT) scan by Brown et al., determined that the breakdown is probably closer to $70 \%$ mixed bony-membranous and $30 \%$ bony.(2) This makes intuitive sense since in only very unusual circumstances is the defect merely a thin membrane amenable to rupture and dilation. CT scan findings usually include a combination of narrowed posterior nasal cavity, lateral bony obstruction, medial vomerine bony obstruction and membranous obstruction (Fig. 1, 2, 3). Neonates are considered to be obligate nasal breathers, dependent on a patent nasal airway for ventilation. However, this is not true for up to $40 \%$ of neonates in one study.(3) Bilateral choanal atresia is a medical urgency, but not a surgical emergency. This allows for an orderly evaluation of potential associated features. The Constellation of physical findings known as the CHARGE association contains ocular colobomas, heart defects, choanal atresia, retarded growth, genitourinary hypoplasia, and ear abnormalities. (4) From an anesthetic standpoint, preoperative cardiac evaluation is mandatory.

*ENT Department Ahmed Maher Teaching Hospital
Roederer first described choanal atresia in 1755 as noted in a text by Otto. (5) The 5 primary methods are transpalatal, transnasal, sub-labialtransnasal, transantral, and transseptal approaches. Pirsig provided a very thoughtful and historical review of the literature in 1986.(6) Of these, the transpalatal and transnasal approaches provide the best result with least morbidity.(7)With the advent of endoscopic equipment and powered instrumentation, the most popular and successful method over the past decade has been the transnasal technique.(8-10) Even for revision surgery, most surgeons prefer an endoscopic approach due to the potential morbidity of cross-bite, palatal fistula, and possible dentoalveolar growth issues from the transpalatal method. (6)

\section{PATIENTS AND METHODS}

A retrospective medical record analysis was performed of patients with congenital choanal atresia seen at Ahmed Maher Teaching Hospital, between January 2000 and June 2005. Eight patients with such a diagnosis were treated by the transnasal endoscopic surgical technique. From January 2000 to December 2003, 5 patients were treated endoscopically using traditional sinus instrumentation, and from January 2004 to June 2005, 3 patients were treated with the endoscopic drill-out technique. Patients' age at the time of treatment, sex, the type of stenosis (Bony or mixed), laterality (Bilateral or unilateral), the type of instrument used, and follow-up results are shown in the table. With standard nasal endoscopic equipment and nasal powered instrumentation available, oxymetazoline hydrochloride spray is applied to the nasal cavity 15 minutes before the patient is transported to the operating department. On arrival, general anesthesia is induced. Additional nasal decongestion is obtained by applying a solution of $2 \%$ lidocaine hydrochloride and $0.25 \%$ phenylephrine hydrochloride to neurosurgical 


\section{Mohamed Elsayed}

cotton pledgets that are carefully placed in the nasal cavity. Using a $4.0 \mathrm{~mm}, 0^{\circ}$ telescope, both sides of the nasal cavity are inspected, and the atretic plate is carefully identified. A solution of 2\% lidocaine with 1:100 000 epinephrine is administered with a spinal needle under direct visualization to the atretic plate and posterior septum. In a patient with bilateral atresia, the anesthetic is administered to both sides during the inspection. The eyes are taped closed at the lateral canthus and exposed in the operative field. A tonsil sponge is positioned high in the nasopharynx, distending the soft palate caudally. The sponge serves as a landmark during the procedure. Using a power soft tissue shaver under endoscopic visualization, the mucosa over the atretic plate is carefully removed. A round cutting burr then replaces the tissue shaver on the powered handpiece. Staying posterior, inferior, and medial in the nasal cavity, the surgeon perforates the atretic bony plate. Visualizing the tonsil sponge previously placed in the nasopharynx ensures correct fenestration. Once this is ascertained, the new choana is completed by drilling laterally, enlarging to the lateral edge of the nasopharynx. Backbiting forceps are then used to reduce a portion of the posterior bony septum. This further enlarges the neochoana (Fig. 4, 5, 6) no stent was used. Antibiotic medications and an isotonic sodium chloride nasal spray are administered postoperatively.

\section{RESULTS}

Eight patients were treated for CCA with the transnasal endoscopic technique. Of these, 5 patients were treated using powered instruments (2004-2005) and 3 patients had the endoscopic procedure with traditional biting equipment (2000-2003).Two patients were male, and 6 were female. The age at the time of treatment ranged from 2 days to 15 years with an average of 3 years. Six patients had a unilateral atresia and 2 had bilateral atresia. Computed tomography scanning was used to determine if the atresia were of the bony ( 2 patients) or of mixed bony and membranous elements ( 6 patients). All 8 patients were treated endoscopically with either the use of power instruments or conventional biting tools to open the bony aspect of the atresia (Table).

\begin{tabular}{|c|c|c|c|c|c|c|}
\hline \multicolumn{7}{|c|}{ Transnasal Endoscopic Choanal Atresia Repair, 2000 to $2005(\mathrm{~N}=8)^{*}$} \\
\hline $\begin{array}{c}\text { Patient } \\
\text { No./Sex/Age }\end{array}$ & Laterality & Atresia & $\begin{array}{c}\text { Type } \\
\text { Instruments }\end{array}$ & $\begin{array}{l}\text { Follow- } \\
\text { up }\end{array}$ & Result & Comments \\
\hline $1 / F / 3 y$ & Unilat & Bony & $\mathrm{CB}$ & $4 \mathrm{y}$ & Patent & $\begin{array}{l}\text { Granulation tissue } \\
\text { removed } 1 \text { wk }\end{array}$ \\
\hline $2 / F / 5 y$ & Unilat & Mixed & $\mathrm{CB}$ & $\begin{array}{c}4 \text { y } 10 \\
\text { mo }\end{array}$ & Patent & $\begin{array}{l}\text { Patient had restenosis } \\
\text { at } 1 \mathrm{mo} \text {. requiring } \\
\text { endoscopic revision }\end{array}$ \\
\hline $3 / F / 2 y$ & Unilat & Mixed & $\mathrm{CB}$ & $\begin{array}{l}3 \text { y } 2 \\
\text { mo }\end{array}$ & Patent & \\
\hline 4/F/15 y & Unilat & Mixed & CB & $\begin{array}{c}3 \mathrm{y} 4 \\
\text { mo }\end{array}$ & Patent & $\begin{array}{l}\text { Concurrent } \\
\text { septoplasty }\end{array}$ \\
\hline $5 / \mathrm{M} / 4 \mathrm{y}$ & Unilat & Bony & $\mathrm{CB}$ & $\begin{array}{c}2 \text { y } 11 \\
\text { mo }\end{array}$ & Patent & $\begin{array}{c}\text { concurrent } \\
\text { adenoidectomy }\end{array}$ \\
\hline $6 / F / 2 y$ & Unilat & Mixed & Drill & $\begin{array}{c}2 \text { y } 7 \\
\text { mo }\end{array}$ & Patent & $\begin{array}{c}\text { concurrent } \\
\text { adenoidectomy }\end{array}$ \\
\hline 7/F/1 wk & Bilat & Mixed & Drill & $2 \mathrm{y}$ & Patent & \\
\hline $8 / \mathrm{M} / 2 \mathrm{wk}$ & Bilat & Mixed & Drill & $\begin{array}{c}1 \text { y } 3 \\
\text { mo }\end{array}$ & Patent & \\
\hline
\end{tabular}

After the operation, no stent left. Patent choanae resulted in all patients. One patient who had the endoscopic drillout procedure had restenosis 1 month after primary repair, with a subsequent successful endoscopic drill-out revision. In 1 patient who had endoscopic conventional instrument repair, granulation tissue was noted after a week, and the tissue was carefully removed endoscopically without recurrence. Two patients had concurrent adenoidectomy at the time of the atresia repair. Concurrent septoplasty done in one patient (15 years).

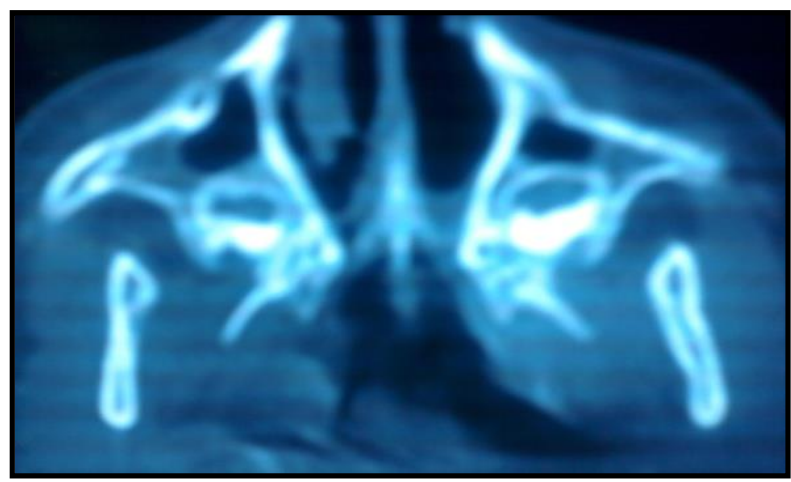

Fig. 1: Axial CT of bilateral

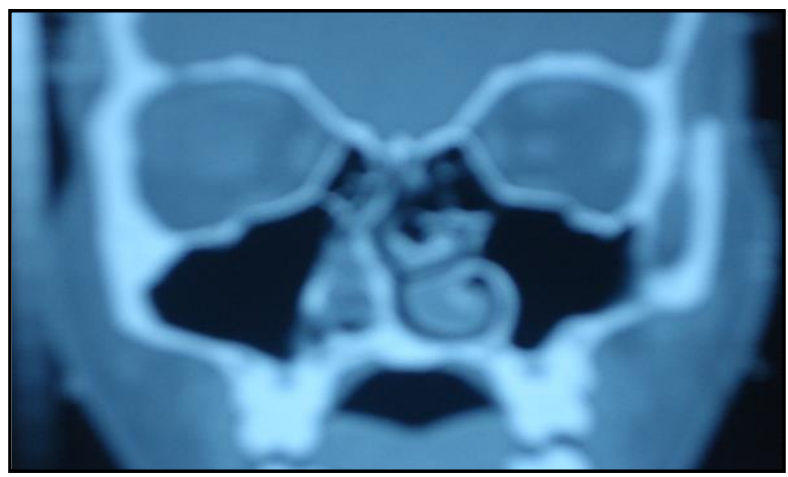

Fig. 2: Coronal CT of Rt.

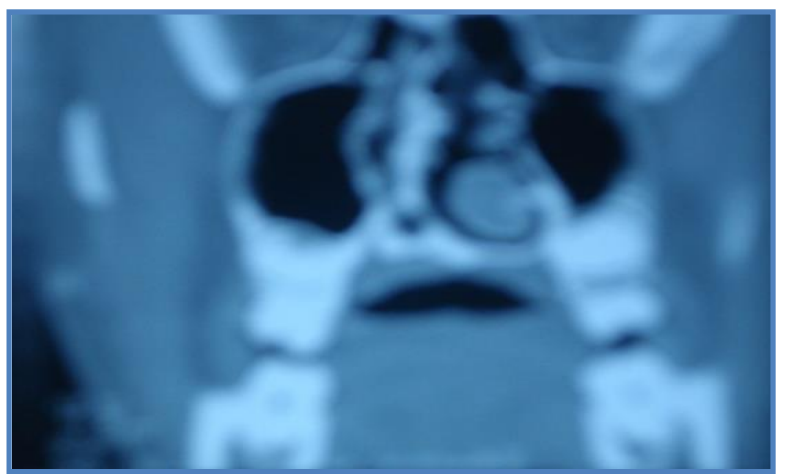

Fig. 3: Coronal CT of Rt. Choanal Atresia

with severe deviated septum

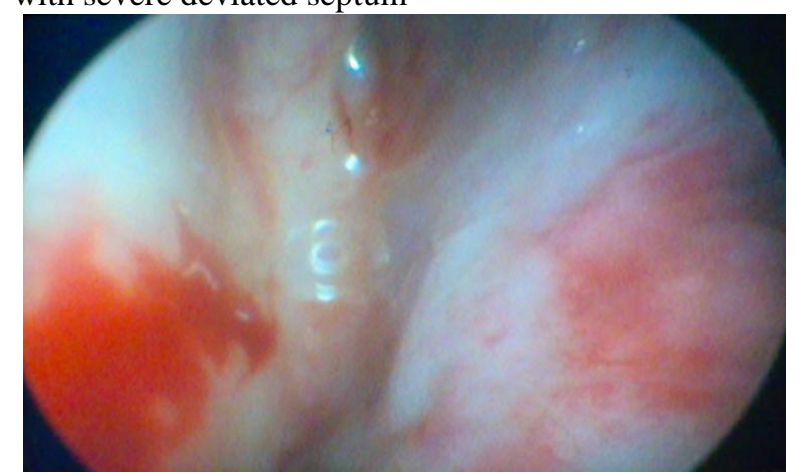

Fig. 4: Enoscopic view of Rt.atresia 


\section{Transnasal Endoscopic...}

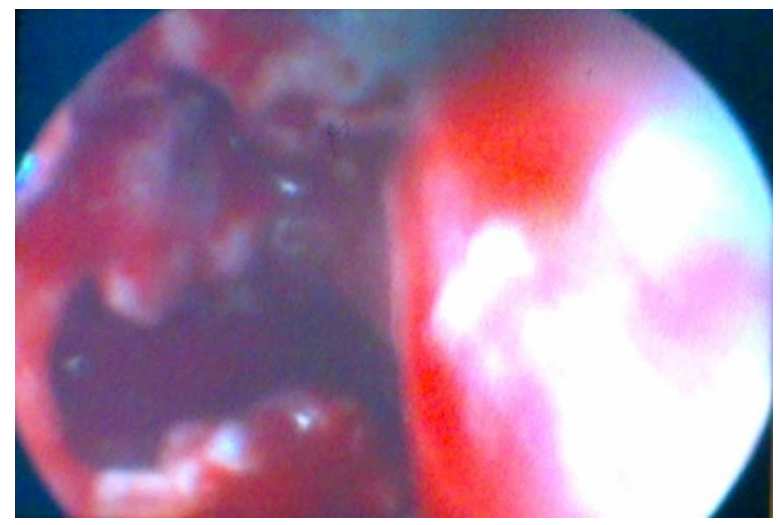

Fig. 5: Endoscopic view showing removal of lateral part of Rt. atretic plate

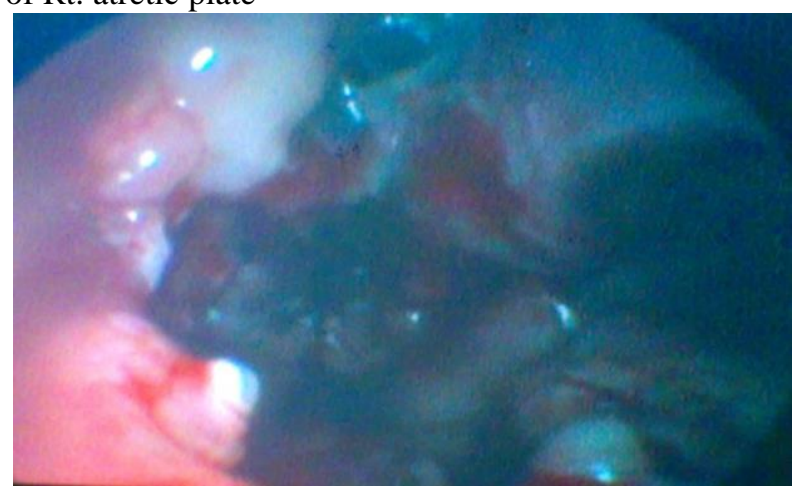

Fig. 6: Enoscopic view of nasopharynx after opening atretic plate+Adenoidectomy

\section{DISCUSSION}

Eight patients were observed postoperatively, with the longest follow-up being 4 years in the conventional instrumentation group and 2 years 7 month in the powered instrumentation group. Richardson and Osguthorpe (8) and Freng (11) have suggested that if restenosis occurs, it will occur within the first 12 months of the operation. All of our patients have been observed longer than a year. Hundreds of articles have been published on choanal atresia. This alone is evidence of the difficulties and controversies otolaryngologist-head and neck surgeons encounter in the management and surgical treatment of this disorder. Surgeons who perform surgical repair of choanal atresia have sought a technique that offers direct access, good visualization, short operating times, and low morbidity. The transnasal endoscopic technique with power instrumentation fulfills these goals. Stankiewicz (12) was one of the first to report the use of endoscopic instruments for choanal atresia repair. Using the otologic drill and conventional instruments, the excellent visualization provided by performing the technique endoscopically resulted in success in 3 of 4 patients. Stankiewicz explains, however, that injury to the nasal columella by the rotating otologic drill shaft is a possible complication. Kamel (9) reported success in 5 patients with the use of this technique, but all 5 were older children with unilateral atresias. In 1995, Lazar and Younis (10) reported a series of 10 patients who were treated with the transnasal endoscopic technique with conventional endoscopic instruments. In their study, 2 failures occurred in newborns with bilateral atresia. Success was uniformly obtained in older children with unilateral atresia. Therefore, they advise the use of this technique for patients aged 3 years or older with unilateral atresia. With endoscopic nasal and sinus surgical procedures more popular, instruments that allow better visualization and more surgical precision continue to be developed. Power-suction soft tissue shavers and drills are believed to be less traumatic to nasal tissue and allow better tissue healing. In addition, the attached suction apparatus facilitates the removal of blood and debris, providing continued visualization and a safer surgical technique. (13) Josephson, (14) strongly advocates the use of telescopic visualization for endonasal operations. The direct access, higher optics, and excellent visualization offered with the nasal telescopes enables a surgeon to safely correct the difficult anatomical areas that have caused high failure rates in the past, i.e., the lateral bony narrowing and the posterior septum. We believe that this was one of the reasons for the high success rate in our series in all age groups, with either laterality of atresia, and with all types of stenosis. Congenital choanal atresia can be successfully treated by the endoscopic transnasal approach in all age groups. Special attention to the following critical points in the surgical procedure has contributed to our high success rate: The prevention of excessive trauma to mucosa diminishes the formation of granulation tissue.(15) As has been reported,(14) the newer soft tissue power shaver causes less tissue injury with more rapid healing. An adequate amount of lateral bony wall and posterior septum must be safely removed. (3) The $4.0 \mathrm{~mm}, 0^{\circ}$ telescopes provide superior visualization of these trouble areas. In addition, the new nasal power instruments offer both soft tissue shavers and bone-cutting drills with protective sheaths to prevent accidental trauma to nonsurgical areas. Stents have been used in most, if not all, reported surgical procedures. Many authors believe that stenting prevents postoperative restenosis. The duration and material of stenting vary from one study to another, and the former can range from several weeks to months. $(2,10,16)$ The benefits vs. the risks of stenting after repair has been hotly debated in the otolaryngology literature for all airway procedures.(17) Stents cause discomfort, localized infection and ulceration, circumferential scar tissue, and injury to surrounding normal tissues.(16) Once removed, circumferential restenosis is common. Indwelling nasal stents are difficult to manage, easily crust and clog (causing a functional stenosis or atresia during the period of stenting), and may migrate or break. Regardless of surgical approach, published reports of surgery using stents demonstrate an overall failure rate of about $30 \%$. (7, 10-12, 17, 18). Stents are associated with local infections and pain, formation of granulation tissue, and nasal synechia. Stent management is often complicated by migration or excessive pressure on the nasal ala. (19) Our results compare favorably with those of other endoscopic series 


\section{Mohamed Elsayed}

and clearly suggest that postoperative stenting is not necessary, provided that the nasal cavity is washed with abundant saline, especially in small children. Gastroesophageal reflux has also been suspected to induce choanal restenosis and should be looked for and treated when present. (20) The efficacy of topical mitomycin in selected cases (e.g., more than 2 failed procedures or bilateral choanal atresia with narrow nasopharynx) needs further investigation, but it has been suggested that this antibiotic can reduce the risk of choanal restenosis. (21)

\section{CONCLUSION}

The transnasal route with the use of endoscopes offers excellent visualization of the posterior nasal defect in patients with choanal atresia and does not require nasal stenting. Traditional endoscopic biting instruments have proved effective in the treatment of these patients, but with new power-suction instruments available for endonasal surgical procedures, the success rate of the repair of choanal atresia is excellent, with decreased tissue trauma and greater ease in removing the bony choanal abnormality. Transnasal endoscopic drill-out repair with power instrumentation is our mode of choice for the correction of choanal atresia.

\section{REFERENCES}

1. Fraser JS. Congenital atresia of the choanae. Br J Med 1910;2: 1698-701.

2. Brown OE, Pownell P, Manning SC. Choanal atresia: a new anatomic classification and clinical management applications. Laryngoscope 1996; 106: 97-101.

3. Miller MJ, Martin RJ, Carlo WA, et al. Oral breathing in newborn infants. J Pediatr 1985; 107 : 465-9.

4. Kaplan LC. The CHARGE association: choanal atresia and mu-ltiple congenital anomalies. Otolaryngol Clin North Am 1989; 22: 661-72.

5. Cumberworth VL, Diazaeri B, Mackay IS. Endoscopic fenestration of choanal atresia. J Laryngol Otol. 1995;109:31-35.

6. Pirsig $W$. Surgery of choanal atresia in infants and children: historical notes and updated review. Int J Pediatr Otorhinolaryngol 1986; 11: 153-70.

7. Richardson MA, Osguthorpe JD. Surgical management of choanal atresia. Laryngoscope 1988; 98:915-8.
8. El-Guindy A, El-Sherif S, Hagrass $M$, et al. Endoscopic endonasal surgery of posterior choanal atresia. J Laryngol Otol 1992; 106: 528-9.

9. Kamel R. Transnasal endoscopic approach in congenital choanal atresia. Laryngoscope 1994; 104: 642-6.

10. Lazar RH, Younis RT. Transnasal repair of choanal atresia using telescopes. Arch Otolaryngol Head Neck Surg 1995; $121: 517-20$.

11. Freng A. Surgical treatment of congenital choanal atresia. Ann Otol Rhinol Laryngol.1978; 87: 346-348.

12. Stankiewicz JA. The endoscopic repair of choanal atresia. Otolaryngol Head Neck Surg. 1990; 103: 931937.

13. Gross CW, Becker DG. Power instrumentation in endoscopic sinus surgery. Operative Technique. Otola-ryngol Head Neck Surg.1996; 7: 236-241.

14. Josephson DG; Christopher LV, William CG, Charles W. Transnasal endoscopic approach in congenital choanal atresia, long term results. Arch Otolaryngol Head Neck Surg.1998; 124: 537-540.

15. Singh B. Bilateral choanal atresia: key to success with the transnasal approach. J Laryngol Otol.1990; 104:482-484.

16. Wiatrak BJ. Unilateral choanal atresia: initial presentation and endos-copic repair. Int J Pediatr Otorhinolaryngol. 1998; 46: 27-35.

17. Deutsch E, Kaufman M, Eilon A. Transnasal endoscopic management of choanal atresia. Int J Pediatric Otorhinolaryngol. 1997; 40: 19-26.

18-Abbeele T, Franc, ois M, Narcy P, Transnasal Endoscopic Treatment of Choanal Atresia Without Prolonged Stenting. Arch Otolaryngol Head Neck Surg. 2002; 128: 936-940.

19-Schoem SR. Transnasal Endosc-opic Repair of Choanal Atresia:Why Stent. Otolaryngol Head Neck Surg.2004; 131:362-366.

20. Beste DJ, Conley SF, Brown CW. Gastroesophageal reflux complicating choanal atresia repair. Int J Pediatr Otorhinolaryngol. 1994; 29:51-58.

21. Ingrams DR, Volk MS, Biesman BS, Pankratov MM, Shapshay SM. Sinus surgery: does mitomycin C reduce stenosis? Laryngoscope. 1998; 108: 883-886 